\title{
What Police Say About Crime Prevention through Environmental Design (CPTED) Training in Two Jurisdictions (England/Wales and New South Wales, Australia)
}

\section{Introduction}

Crime Prevention through Environmental Design (CPTED) refers to the manipulation of the built environment to reduce the opportunity for crime, disorder and the fear of crime (Crowe, 2000; Armitage, 2013). CPTED is underpinned by a number of principles (Poyner, 1983; Cozens et al, 2005; Armitage, 2013; Montoya et al, 2016; Armitage \& Monchuk, 2017). While opinions vary regarding the most important principles, Armitage (2013) states that there are five key principles or components: i) physical security - to ensure that robust security measures are installed on individual dwellings to withstand attack from offenders; ii) surveillance - to ensure residents are able to observe the areas surrounding their home and their neighbourhood and witness, challenge or report any suspicious behaviour; iii) movement control - to ensure that opportunities for access, egress and through movement are minimised to prevent unauthorised access; iv) management and maintenance - refers to the importance of ensuring that a development is free from graffiti, vandalism and litter and v) defensible space - refers to the clearly defined ownership of space in a neighbourhood and encourages and promotes residents to feel a sense of responsibility for the areas adjacent to their home.

CPTED is a multi-faceted approach to crime reduction and depends on a number of agencies and roles, including urban designers, planning authorities and housing developers. Police also play an important role in delivering CPTED in many jurisdictions. Designing out Crime Officers (hereinafter DOCOs) across England and Wales and Crime 
Prevention Officers (hereinafter CPOs) across the Australian state of New South Wales are involved in reviewing planning proposals and for encouraging consideration of CPTED principles. DOCOs/CPOs are required to read, interpret and appraise architectural plans and suggest feasible recommendations and design alterations in an attempt to reduce opportunities for crime and disorder through the design and planning process. Research conducted by Monchuk et al (2018) confirms that those officers responsible for the delivery of CPTED are skilled to do so, but highlights the inconsistency in which it is applied amongst individual officers - a concern also raised by practitioners (Local Housing Delivery Group, 2012). This raises important questions regarding the training of these officers, which is the focus of this article.

This paper presents the findings from two projects conducted in two jurisdictions at two different time periods. The first was a comprehensive study conducted with 30experienced DOCOs in 19 police forces across England and Wales in 2014. The second was a study conducted with 36 CPOs from New South Wales Police Force in 2017. Each study collected data on the DOCOs/CPOs views on the levels and types of training and Continued Professional Development (hereinafter CPD) they had undertaken to equip them with the relevant skills to perform their role. Thus, the data presented in this paper is derived from a convenience sample. Seeking the views of these officers is crucial as ultimately it is the police who drive the concept of CPTED (Olasky, 2004) and are responsible for policing the consequences of any poor, criminogenic design (Monchuk, 2019). To the authors' knowledge, this is the first time that practitioners' views on CPTED training provision have been presented. 
The focus of this paper is CPTED which, along with crime prevention more generally, is often considered a peripheral specialism in policing and one that is treated with low status and interest when placed alongside crime fighting (Graef, 1989; Sarre, 1996; Loftus, 2009; Hirschfield et al, 2013). In one study, Honess (2016) found that owing to the diversity of the roles within policing, training was not tailored to individual needs. Indeed, training was often viewed as a 'tick-box' exercise (Honess, 2016). Moreover, Skogan et al (2015) note that there has been a lack of systematic research on police training provision generally. Consequently, this article seeks to add to the limited scholarship in this area, specifically focused on CPTED training and professional development provided to police but with broader implications for police training more generally.

\section{The delivery of CPTED}

CPTED is delivered across England and Wales by DOCOs. One or more such officers are employed within each of the police forces across England and Wales. Historically, the role of a DOCO was undertaken by a serving police officer approaching retirement (Weatheritt, 1986). However, one of the key changes to policing across England and Wales has been the civilianisation of a number of policing roles to reduce expenditure and to allow warranted officers to undertake front-line duties (Newburn, 2003; Neyroud, 2009; HMIC, 2014; Hirschfield et al, 2014). Whilst it remains that in some forces the DOCO role is undertaken by a warranted police officer, the role has been substantially civilianised. DOCOs tend to be either: i) retired police officers who have returned to the force in a civilian support staff role; ii) civilian support staff with no prior policing or built environment experience; iii) civilian support staff with built environment experience or iv) a warranted police officer (Wootton et al, 2009; Monchuk, 2016). Within one police 
force (Greater Manchester ${ }^{1}$ ) DOCOs are former built environment professionals, such as planners and architects, and are skilled in design, planning and the interpretation of plans (Blyth, 1994; Monchuk, 2011; 2016 \& in 2019).

Across the Australian state of New South Wales (hereinafter NSW), CPTED is delivered by New South Wales Police Force CPOs. CPOs work across 58 Police Area Commands (a geographically defined policing area) that cover 129 local councils ${ }^{2}$. In contrast to policing in England and Wales, the civilianisation of roles is less pronounced (Neyroud, 2009). Thus, CPOs across NSW are sworn police officers. A review of duties typically undertaken by CPOs suggests the role encompasses a variety of tasks, of which the delivery of CPTED is but one. Additionally, as CPOs are police officers, they may be required to undertake operational policing duties as per the First Response Policing Agreement (NSW Police Force, 2015). This might vary from a small number of hours to longer periods, reducing the time they can dedicate to their crime prevention duties.

Whilst there is an emerging body of knowledge focusing upon those responsible for the delivery and application of CPTED (see for example Wootton et al, 2009; Clancey et al, 2014; Monchuk, 2016; Monchuk et al, 2018; Clancey et al, 2018), there is little data specifically reporting upon the training and development of those responsible for applying the principles of CPTED. By bringing together two datasets that focus upon

\footnotetext{
${ }^{1}$ The team responsible for delivering CPTED across Greater Manchester is referred to as Greater Manchester Police Design for Security Consultancy (GMP DFSC).

${ }^{2}$ It is important to note that there are a number of council amalgamations currently taking place and so these numbers are subject to change.
} 
CPTED training for specialist officers from studies conducted in England and Australia, it provides a comparative account as to the training, education and development opportunities officers receive to deliver their CPTED role. It seeks to examine some of the key challenges faced when attempting to drive long-term crime prevention initiatives within a reactive policing environment.

\section{Training and CPTED}

The application of CPTED is a specialised skill, as noted by a Victorian Parliamentary Inquiry: 'The application of designing out crime principles and CPTED is a highly specialised and technical skill. CPTED is not something that can be 'done' easily without previous experience in the area' (Victorian Parliamentary Inquiry Drugs and Crime Prevention Committee, 2013 p. 304). As previously stated, it differs from other policing functions and decisions made can impact upon the design of developments, and the residents living in such developments, for a substantial amount of time. As such it requires adequate training, education and experience to help improve professional practice.

Across England and Wales, DOCOs have been required to complete a 10-day training course which is delivered by Police Crime Prevention Initiatives Limited (PCPI) (and prior to that the College of Policing). The course includes modules such as: criminological theory; the principles of CPTED; the planning process; the application of CPTED and multi-agency working. At the time of writing, PCPI are seeking to professionalise the training delivered to DOCOs (which accords with the College of Policing's overall strategic aim) (Rogers \& Smith, 2018). PCPI have introduced the UK's first Police Crime Prevention Academy and introduced externally accredited learning and development 
qualifications (PCPI, 2016). There are now three levels of qualification for those working within the crime prevention arena: i) level 3 award - Introduction to Crime Prevention; ii) Level 4 certificate - Crime Prevention for Practitioners and iii) Level 5 diploma Crime Prevention (Designing out Crime). It is the Level 5 diploma that is of relevance to DOCOs. However, a review of the outline content suggests that it largely remains as before in terms of length and content. This is the only dedicated training that DOCOs receive on how to assess plans and drawings, irrespective of their background. The cost to attend this training is $£ 2550$ (or approximately $\$ 4400$ AUD) which is payable by the DOCOs respective force. Police Crime Prevention Initiatives also hold an annual National Training Event. Whilst this event is aimed at DOCOs, attendance is dependent upon DOCOs securing funding to attend from their force.

In New South Wales, CPOs (sworn police officers) are required to undertake the Safer by Design course delivered by the NSW Police Force. This training (originally ten days in duration, but reduced to four-days in recent years) covers the following topics: criminology and crime prevention; core principles of CPTED; identifying crime risk in architectural plans and drawings; lighting, fear and crime; crime risk management and CPTED applications; and councils, planning and design safety (McCamley 2001; NSW Police Force, 2018). This is the only dedicated training that CPOs receive on how to assess plans and drawings. The cost to attend this training is $\$ 1025$ ( approximately $£ 580$ ). There is no other form of CPD dedicated to CPTED, but there are annual/biennial conferences.

\section{Methodology}


This paper brings together the findings from two research projects. The first, predominately qualitative in its approach, was conducted by the lead author as part of her doctoral research in England and Wales (Monchuk, 2016). This comprised semistructured interviews with a sample of 30 DOCOs from 19 different police forces. The sample included DOCOs who were warranted police officers and civilian staff (some with a policing or built environment background). Table 1 provides a summary of participant characteristics. The interview sought to understand the DOCO role and the types of training and CPD they receive to undertake the role. Interviews were digitally recorded and the audio recordings transcribed verbatim.

Table 1: Background of participants included in Monchuk's (2016) study

\begin{tabular}{|l|c|}
\hline \multicolumn{1}{|c|}{ Background } & Number of participants \\
\hline Serving police officer & 6 \\
\hline Retired police officer & 11 \\
\hline Police civilian staff & 8 \\
\hline Former built environment professional & 5 \\
\hline
\end{tabular}

The second project was conducted by the authors and colleagues ${ }^{3}$ in Australia to obtain NSW Police Force CPOs' perspectives on CPTED (Clancey et al, 2018). Data collection involved administering a short survey and then conducting four focus groups with a total of 36 CPOs (predominantly from the Sydney metropolitan area). All participants were sworn police officers - 5 were Constables and 31 Senior Constables. Both quantitative

\footnotetext{
${ }^{3}$ Justin Ellis and Jessica Anderson.
} 
and qualitative data relating to training and $\mathrm{CPD}$ were obtained and the focus groups were digitally recorded and the audio recordings transcribed verbatim.

Thus, the data presented in this paper comprises the views of a total of 66 participants responsible for the delivery of CPTED within their relevant jurisdictions - 30 from England and Wales and 36 from NSW As highlighted above, the majority of the 66 participants $(80 \%)$ had a background in policing (they were either serving or retired police officers). In compiling this paper, all transcripts were reviewed and data pertaining to training, education and development analysed thematically (Matthews \& Ross, 2010).

\section{Findings}

Thematic analysis of the two datasets revealed that irrespective of jurisdiction, three key themes emerged from the data. First, the participants indicated that the initial training they had received did not adequately prepare them for the DOCO/CPO role. Second, the participants stated that the training they had received did not provide them with the confidence to assert their recommendations and challenge the views of other built environment professionals. They were also concerned about the lack of consistency in the application of CPTED principles across DOCOs/CPOs, further impacting upon confidence levels. Third, the participants bemoaned the lack of any dedicated and comprehensive professional qualifications available for them to complete along with any opportunities for regular CPD. Each theme will be discussed in turn and supported with relevant quotations from each of the two datasets.

\section{Lack of preparation for undertaking the DOCO/CPO role}

Analysis of the data revealed that the participants found that their respective courses provided a useful, introductory insight and overview of the principles of CPTED. However, it was felt that the courses failed to provide any detail as to what the 
$\mathrm{DOCO} / \mathrm{CPO}$ role entailed on a day-to-day basis (such as the process of liaising with local planners, obtaining planning applications etc). This is apparent in the below quotations from two serving police officers:

...the course gave you those foundations [but] it certainly didn't teach me how to do the role (Participant 5 - England \& Wales).

I really think our training is very poor when it comes to doing development applications. The CPTED course is very interesting but it does not teach you when the rubber hits the road (Focus Group 2 - New South Wales).

The data revealed that once this initial training has been completed (10 days in England and Wales and 4 days in NSW), DOCOs/CPOs are then immediately tasked with undertaking the role, often without the support or guidance of an experienced DOCO/CPO. Participants described that they tended to find this overwhelming and stated how the DOCO/CPO role was far removed from any reactive crime prevention work that they had undertaken during their operational policing duties. Participant 5 (England \& Wales) discussed how they found the CPTED training 'a steep learning curve' and one that was dissimilar to their policing role: '...I had to take my police head off and think of things completely different...it was completely different from crime prevention going out and giving advice'. One Australian participant explained how after completing the course, she spent time reviewing a number of historic development applications to try and further prepare her for the CPO role: 'I got back and panicked and thought 'oh god now I have to do this!' So I did a lot of just looking at old ones' (Focus Group 4 - New South Wales).

Conversely, one of the former built environment professionals from the study conducted in England and Wales found the initial DOCO course well balanced. They stated that whilst there were some parts of the course that they found difficult, owing to their previous role and experience in design related field, they were able to easily interpret the architectural drawings. Indeed, this participant stated they were able to impart their knowledge and assist a fellow colleague during the training course: 
...I find it easy enough to understand the drawings within a couple of minutes. I'll know what I am looking at and how it fits together...I thought. Well that's easy so I'll teach the guy next to me as well, as he was struggling but I was sort of able to offer assistance (Participant 3 England \& Wales).

\section{Lack of confidence in assessing planning applications and concerns regarding the inconsistent application of CPTED principles}

As a consequence of the limited training, participants stated that they lacked confidence in undertaking their DOCO/CPO role. Participants stated that they felt insufficiently trained to critically appraise planning/development applications, thus lacking confidence to challenge aspects of a proposed design with key built environment professionals (such as architects and developers). Participants discussed how built environment professionals are in receipt of academic and professional qualifications and undertake regular CPD to undertake their role. One Australian participant stated that they found it 'daunting' to challenge built environment professionals and critique large and often expensive designs:

You've got architects designing these things, you've got a lot of people paying a lot of money to design and draft up these plans, and you're given four days and you're an expert in it. You're an expert with four days' training. Arguing with people, developers, who have a lot of money, people with a lot of experience. It's a bit daunting (Focus Group 1 - New South Wales).

Participant 17 (England \& Wales) described frustrations at not having a comprehensive evidence base from which to draw upon when attempting to justify some of their crime prevention comments and recommendations. They outlined how an architect may justify their position based upon design principles, yet it is difficult for a DOCO to provide any comprehensive evidence in response as often any response is based upon previous experience and anecdotal accounts:

If you've got an architect who says I would do this because of blah, blah, design, design, you're thinking 'well I know what I want to say here but I've nothing to back it up other than maybe a bit of experience from 
another site' so it's anecdotal rather than having any depth to it. (Participant 17 - England \& Wales)

Whilst there is an increasing amount of academic studies that evaluate the link between design features and crime (for example Armitage et al, 2011) perhaps it is the case that such research is not being included nor referred to in training and CPD or being readily disseminated to practitioners. Participants also spoke of the importance of having local examples of good practice to help ensure that this resonated with the planning officers. Nonetheless, the lack of a comprehensive evidence base and the need to rely upon anecdotal information to justify recommendations, raises questions about the consistency with which CPTED is both applied and delivered amongst DOCOs/CPOs. One participant questioned the consistency of advice and recommendations provided across NSW:

...you get a $D A$ [development or planning application] in front of you... and I'm sure there's 15 of us here, we probably all do 15 different things. (Focus Group 2 - New South Wales).

Both sets of participants described how they lack confidence in challenging development applications, especially if the DOCO/CPO is summoned to attend court and provide their 'expert' opinion at a planning appeal:

...every application has the potential to go to a Land and Environment Court where they require the expert witness. You are the expert with four days' training... (Focus Group 1 - New South Wales).

The participants outlined that they do not feel that they possess the relevant professional qualifications to challenge built environment experts and it evident that this impacts upon their confidence levels:

...we're very vulnerable because this is why I won't stand...I will object and I'll maybe do written representations, but I won't stand up in a court to do any defence of my objection because I'll be torn apart! What professional qualifications do I have? (Participant 12 - England \& Wales) 
I'm just a constable who's done a four-day course and I'm commenting on a multimillion dollar development here, going through the courts. I wouldn't feel comfortable sitting in a Land and Environment court talking about my qualifications to comment on this and what you should be doing. (Focus Group 2 - New South Wales)

\section{Lack of a dedicated qualification and opportunities for Continued Professional Development (CPD)}

The lack of a dedicated qualification and opportunities for CPD was identified as a concern across all participants. Quantitative data ${ }^{4}$ collected from the survey conducted with the CPOs in NSW revealed that 23 CPOs (64\%) had not received any additional CPTED training upon the completion of the Safer by Design training course with 28 (78\%) stating the need for additional training opportunities.

Whilst many participants stated that they would relish the opportunity for CPTED to become more integrated into the design and planning process and their recommendations be a key requisite for planning approval, it is imperative that they receive more training and CPD. As highlighted in the following quotations, the NSW CPOs advocated the need for a professional qualification to help develop their skillset and confidence:

...the four day course is useless for what is expected of us. Really great for the problem solving policing side of it, but not any good for the Development Application side of it. You need to have some tertiary qualification outside of that because you are just going to - you're not going to be heard and you're not going to be considered, and it's evident because you don't have the education to back what you're saying (Focus Group 4 - New South Wales).

I think if you want us to have more weight in our opinions to council, we need the training. We need recognised qualifications...(Focus Group 1 - New South Wales)

\footnotetext{
${ }^{4}$ Quantitative data were available for this theme only.
} 
The requirement for qualifications was also identified as crucial amongst the DOCOs interviewed in England and Wales. As one participant stated, it is important that any qualification is recognisable and accredited to help demonstrate that a DOCOs knowledge has been tested:

...look at the training and revamp it more to, certainly a diploma first stage or degree level qualification which is really recognisable and accredited to other professional people which they would recognise and respect as somebody who's got some tested knowledge and applied knowledge... (Participant 14 - England \& Wales).

One participant from England discussed how the lack of qualifications, hinders the career development of individual officers: 'Somebody asked me the other day 'where can I go get another qualification' because he said otherwise I haven't got anything career wise, progression wise (Participant 9 - England \& Wales). However, it is important to reiterate that at the time of writing, PCPI is launching a Police Crime Prevention Academy, which seeks to introduce a range of accredited qualifications. It is envisaged that this will help to address these concerns.

As well as establishing a formal and recognised qualification, the participants discussed the requirement for regular CPD to formally refresh their learning. Almost all participants stated that once the initial training course has been completed, there is no opportunity to undertake any refresher (unlike in other areas of policing). 'There're no refreshers, so in theory you do your course and that's it' (Participant 21 - England \& Wales). One NSW CPO stated that regular CPD would help ensure that they are kept abreast of any changes to policy, standards and research since they completed the initial course:

I personally would like some more training and development in CPTED. I do a lot of them and I develop each time I do them myself, but it would be nice to keep having formal refreshers of what I'm doing. There's always things changing in the space and improvements and advances in technology, so it would be nice to have a regular refresher of what's new in the space and what we can do (Focus Group 3 - New South Wales) 
As alluded to in the quotation above, owing to the lack of training and CPD available, CPOs and DOCOs often use their past experiences or specific examples of developments they have worked on to help inform their work. This notion of self-learning is also perhaps a reflection of the way in which DOCOs and CPOs tend to work across large geographical areas (such as individual forces in England and Wales, or Police Area Commands in NSW). Thus, the role can be one which is isolating. One NSW CPO suggested that regular and informal opportunities to network with colleagues from other Police Area Commands are useful to compare and contrast experiences and discuss specific issues. This also has the potential to help improve consistency in the advice and recommendations provided.

...networking between us all is really good because there's things that each of us come up against that others might not, and just being able to chat... (Focus Group 4 - New South Wales Police).

The usefulness of an informal supportive network was also highlighted by the DOCOs interviewed in England and Wales. Participant 10 stated that DOCOs would telephone or email colleagues either within or across force to seek their advice:

'...there's a load of proactive guys, so you just phone them up - what have you done and have you ever come across this?' (Participant 10 - England \& Wales).

Whilst such networks are important, there is the possibility of the dissemination of poor practice. It may be the case that a DOCO/CPO suggests a possible solution that appeared to work for one scheme or location, yet they have no evidence to confirm whether it was successful or not.

A key difference between the training and learning provision across England and Wales and NSW is that in the former there is an annual national training event that is hosted by PCPI. This is a two day event comprises a number of presentations and workshops which seek to provide updates on standards and research. This is the only form of training 
provision delivered by $\mathrm{PCPI}^{5}$ and the way in which it is delivered is typical of a conference format, with little opportunity for interaction. There is a fee to attend the event, payable by each individual police force. Whilst PCPI offer a small number of free places to each force, owing to significant cuts in policing budgets, it is not possible for all DOCOs to attend this training event. Often the force will only allow one or two individuals to attend. These officers are then responsible for cascading any updates or learning to colleagues. As this is the only training available to DOCOs, they highlighted their frustrations with this:

The problem is the financial outlay...it's a training need and what should happen is, is that every Designing out Crime Officer in the country should be able to attend the course, irrespective of the financial situation. So, if they can't be funded then they should go anyway. (Participant 1 - England \& Wales)

Participant 1 went on to state that the CPD for other functions of the police require each individual officer to attend:

You don't get people learning to shoot a gun and you get a few sent to do it and come back and then show others how to do it. Basically, everybody should be going on it and that, really being honest, shouldn't have any financial implication.

\section{Discussion \& Conclusion}

This paper provides a review of the training and CPD available to officers responsible for the delivery and application of CPTED. Unlike other aspects of policing, crime prevention often receives little attention as it does not yield immediate results (Graef, 1989; Sarre, 1997; Schneider \& Kitchen, 2007; Loftus, 2009; Byrne \& Pease, 2008;

\footnotetext{
${ }^{5}$ Other training courses external to PCPI are available, but are chargeable.
} 
Hirschfield et al, 2014). However, it is well documented that opportunities for crime and disorder can be prevented through the design and planning of the built environment (Armitage \& Monchuk, 2011; Armitage et al, 2011).

Research conducted into DOCOs in England and Wales (Wootton et al, 2009; Monchuk, 2016) and CPOs in NSW (Clancey et al, 2018) highlights key differences in the role (especially their professional backgrounds). However, analysis of the data presented within this paper reveals that the participants in the two jurisdictions were making the same argument - that current CPTED training and CPD provision fails to adequately prepare officers for the role. Indeed, you could not differentiate between the jurisdiction on the basis of the comments made.

Many of the 66 participants of the two studies indicated that they have a policing background and that additional training and CPD is required to ensure that they can interpret and critique planning applications. The authors argue that DOCOs and CPOs should be given the resources, training and CPD they require to help professionalise the role and finesse their skill to ensure they exhibit it to a consistently high level. This will help to further professionalise the role, addressing concerns regarding the inconsistency of delivery (as highlighted in England by the Local Housing Delivery Group, 2012), and will help to facilitate relationships with planners, urban designers and other key stakeholders. The authors also agree with Cox (2011) that educating police officers (and staff) should be viewed as a long-term process and so the design and regular delivery of meaningful CPD is imperative. As Cox (2011) states:

Educating police officers is far more than providing islands of training and education. It needs to be viewed as a career-long system of learning 
and development with a strong commitment and expectation that officers

will be active participants in their professional development (p.17).

To this end, the authors argue the need for more research to examine the training needs and requirements specific to each officers' professional background to ensure the design and development of a tailored training and CPD programme - one size will not fit all. For example, in England some DOCOs are former built environment professionals and whist well versed in reading and interpreting site plans, are unfamiliar with crime prevention theory. The reverse is the case for those with a policing background.

The authors propose that any training and CPD provision should comprise a mix of informational and practical elements. In terms of information, regular briefings or forums could be co-ordinated. Whilst we are appreciative that such briefings may already occur, what we propose is regular briefings to help ensure that DOCOs/CPOs are regularly kept abreast of national crime trends so that any advice that they provide is commensurate with both national and local crime rates. Forums should also include updates on relevant academic research findings (so that they are up-to-date with evidence on the effectiveness of CPTED) and changes in key policy and guidance which will ultimately impact upon their role and the advice they provide and their relationship with the local planning authority.

In terms of practical CPD elements, DOCOs/CPOs should be provided with the opportunity to meet so that individual development scenarios and case studies can be appraised and synergies and discrepancies in the advice provided can be discussed and clarified. As highlighted by the Victorian Victorian Parliamentary Inquiry Drugs and Crime Prevention Committee (2013) it is important that the design of CPTED training is 
built around an evidence base. A research methodology, such as that conducted by Monchuk et al (2018), can be adopted to help test the approaches used to applying the principles of CPTED and assess the variety of judgements made by DOCOs/CPOs to ensure consistency and that the recommendations made are commensurate to national and local crime risk. In addition, the authors recommend that DOCOs/CPOs undertake a detailed review of a small number of local developments that they commented on annually, with particular focus on crime suffered on these developments. These case studies can systematically document advice provided and any compromises/conflicts and used in conjunction with published academic research. These data would be invaluable in identifying whether there are any specific, and recurring, areas of conflict between CPTED advocates and other agendas. Local case studies will also be a useful resource in helping to brief senior management or operational policing colleagues.

Owing to the fact that both DOCOs and CPOs are located across large geographical areas within their respective jurisdiction, it is unfeasible to suggest that they all meet regularly and in person. This would be impractical. It is suggested that training is delivered through a number of different forums, such as webinars, online training, Computer Aided Design (CAD) or Virtual Reality (VR). Monchuk et al (in press) is also beginning to examine the usefulness of automated planning to assist DOCOs/CPOs in undertaking their initial assessment - this could prove useful for training purposes. It is important to reiterate that at the time of writing, the Police Crime Prevention Academy is about to be launched across the United Kingdom. Whilst this is promising step and will see the introduction of dedicated crime prevention qualifications, it is too early to report on how the academy will continually assess the skillset of DOCOs and also what regular CPD will be provided to ensure that DOCOs remain abreast of updates in standards and research underpinning CPTED. 
Finally, it is important to balance the training required to competently undertake CPTED work and what is feasibly possible given the plethora of other training police officers are required to undertake to ensure that they are equipped to deal with a multitude of challenges to undertake their operational duties (see for example: Ford, 2003; Pane, 2007; Chappell, 2008; Cox, 2011; Herrington \& Pope, 2014). How this is achieved in an already crowded training program and with considerable demands on the time of these officers is difficult to resolve. Police will inevitably argue for needing more training, as has been found in other areas of policing (Pane, 2007 cited in Cox, 2011) but police managers need to balance that with the getting maximum return from their officers, as Ford (2003) argues, a significant amount of funding is used to train officers in skills likely to be rarely used.

In conclusion, the authors argue that, regardless of jurisdiction, it is important that those responsible for the delivery and application of CPTED, are provided with adequate and regular training and CPD opportunities to help undertake their role effectively. There is research to suggest that developments built to the principles of CPTED can experience less crime and disorder compared to those that are not. Thus, it is important that those responsible for its delivery are afforded the support, resources and training they require to help professionalise the role and finesse their existing skill to ensure that CPTED can flourish, while acknowledging that there will always be limits to what can be provided to specialist police roles.

\section{References}

Armitage, R. (2013). Crime Prevention through Housing Design: Policy and Practice. Basingstoke: Palgrave Macmillan. 
Armitage, R., \& Monchuk, L. (2011). 'Sustaining the crime reduction impact of designing out crime: Re-evaluating the Secured by Design scheme 10 years on'. Security Journal, 24 (4), 320-343.

Armitage, R., \& Monchuk, L. (2017). 'What Is CPTED? Reconnecting Theory with Application in the Words of Users and Abusers'. Policing: A Journal of Policy and Practice. DOI: 10.1093/police/pax004.

Armitage, R., Monchuk, L. \& Rogerson, M. (2011). 'It looks good, but what is it like to live there? Exploring the impact of innovative housing design on crime'. European Journal on Criminal Policy and Research, 17 (1), 29-54.

Blyth, A. (1994). 'Fighting Crime with Design'. The Architects Journal. 9: 20-21.

Byrne, S., \& Pease, K. (2008). 'Crime Reduction and Community Safety'. In: T. Newburn. ed. Handbook of Policing. 2nd ed. Abingdon: Taylor and Francis, 341-372.

Chappell, A. (2008). 'Police academy training: comparing across curricula'. Policing: An International Journal of Police Strategies and Management. 31 (1), 36-56.

Clancey, G., Fisher, D., \& Rutherford. A. (2014). 'An Exploratory Study of Crime Risks and the Planning Process'. Crime Prevention and Community Safety: An International Journal. 16 (1), 1-19.

Clancey, G., Monchuk, L., Anderson, J., \& Ellis, J., 2018. Lost in implementation: NSW Police Force Crime Prevention Officer Perspectives on Crime Prevention through Environmental Design. Crime Prevention and Community Safety: An International Journal, 20 (3), 139-153.

Cox, D. (2011). 'Educating police for uncertain times: the Australian experience and the case for a 'normative' approach'. Journal of Policing, Intelligence and Counter Terrorism, 6 (1), 3-22.

Cozens, P., Saville, G., and Hillier, D. (2005). 'Crime Prevention through Environmental Design (CPTED): A Review and Modern Bibliography'. Property Management, 23: 328356. 
Crowe, T. (2000). Crime Prevention through Environmental Design: Applications of Architectural Design and Space Management Concepts. 2nd ed. Boston, MA: Butterworth Heinemann.

Ford, R. E. (2003). 'Saying one thing, meaning another: The role of parables in police training'. Police Quarterly. 6 (1): 84-110.

Graef, R. (1989). Talking Blues: Police in their own words. London: Collins.

Herrington, V., \& Pope, R. (2014). 'The impact of police training in mental health: An example from Australia'. Policing and Society: An International Journal or Research and Policy, 24 (5), 501-522.

Hirschfield, A., Ekblom, P., Armitage, R., \& Roach, J. (2014). 'Holding the line: the sustainability of police involvement in crime prevention'. In: JM, Brown, ed. The Future of Policing. Abingdon: Routledge, 299-316.

HMIC. (2014). Core Business: An inspection into crime prevention, police attendance and the use of police time. Available at: https://www.justiceinspectorates.gov.uk/hmicfrs/wp-content/uploads/core-business.pdf [accessed 04 September 2017].

Honess, R. (2016) The mandatory delivery of ongoing training within the Police Service of England and Wales and its relationship to the andragogical principle of selfmotivation. M.Sc. thesis, Canterbury Christ Church University.

Local Housing Delivery Group. (2012). A Review of Local Standards for the Delivery of New Homes. London: Local Housing Delivery Group.

Loftus, B. (2009). Police culture in a changing world. Oxford: Oxford University Press. 
McCamley, P. (2001). Crime, Design and Urban Planning: From Theory to Practice. Royal Australian Planning Institute: New Planner.

Matthews, B., \& L. Ross. (2010). Research Methods: A Practical Guide for the Social Sciences. Harlow: Longman.

Monchuk, L. (2011). 'The Way Forward in Designing Out Crime?: Greater Manchester Police Design for Security Consultancy'. Safer Communities: a journal of practice, opinion, policy and research, 10 (3), 31-40.

Monchuk, L., 2016. Crime Prevention through Environmental Design (CPTED): Investigating Its Application and Delivery in England and Wales. Doctoral Thesis, University of Huddersfield.

Monchuk, L., (2019) 'A Decade Developing the Delivery of CPTED across Greater Manchester'. In: R. Armitage \& P. Ekblom, eds. Rebuilding Crime Prevention Through Environmental Design: Strengthening the links with Crime Science Abingdon: Routledge, p. 199-215.

Monchuk, L., Pease, K., \& Armitage, R. 2018. Is it just a guessing game? The application of Crime Prevention through Environmental Design (CPTED) to predict burglary. Planning Practice and Research.

Monchuk, L., Parkinson, S. \& Kitchen, J., 6 Feb 2019, (In press) 29th International Conference on Automated Planning and Scheduling: (ICAPS 2019). Association for the Advancement of Artificial Intelligence.

Montoya, L., Junger, M., Ongena, Y. (2016). 'The Relation Between Residential Property and Its Surroundings and Day- and Night-Time Residential Burglary'. Environment and Behavior 48 (4), 515-549.

Neyroud, P. (2009). Civilianization. In: A. Wakefield \& J. Fleming, ed. The SAGE dictionary of policing. London: SAGE, 25-28.

Newburn, T. (2003). Handbook of Policing. 2nd ed. Cullompton: Willan Publishing. 
NSW Police Force. (2018). Safer by Design. [online]. NSW: NSWPF. Available from: https://www.police.nsw.gov.au/safety_and_prevention/policing_in the community/safe r_by_design [Accessed 28 October 2018].

NSW Police Force. (2015). Standard operating procedures for rostering. [online]. NSW: NSWPF. Available from:

https://www.police.nsw.gov.au/_data/assets/pdf_file/0005/533381/Standard_Operating _Procedures_for_Rostering_v1.10.pdf [Accessed 24th August 2018].

Olasky, P. (2004) 'Crime impact statements' Columbia Journal of Law and Social Problems. 37(3), pp. 329-358.

Pane, A. (2007). Examining newcomers' socialisation into an organisation. Part thesis for the Degree of Doctor of Psychology in Industrial and Organisational Psychology: Melbourne University, Australia.

PCPI (2016) SBD launches academy to run new suite of independently certified crime prevention and problem solving courses. [online]. London: PCPI. Available from: http://www.securedbydesign.com/news/sbd-launches-academy-to-run-new-suite-ofindependently-certificated-crime-prevention-and-problem-solving-courses/ [Accessed 28 October 2018].

Poyner, B. (1983). Design Against Crime: Beyond Defensible Space. London: Butterworth.

Rogers, C., \& Smith, B. (2018). 'The College of Policing: Police Education and Research in England and Wales'. In: C. Rogers., \& B. Frevel, eds. Higher Education and Police: An International Perspective. Cham: Springer International Publishing, 87-106.

Sarre, R. (1997). 'Crime Prevention and Police'. In: P. O’Malley., \& A. Sutton, eds. Crime Prevention in Australia: Issues in Policy and Research. Annandale: Federation Press, 71-78.

Schneider, R. \& Kitchen, T. (2007). Crime Prevention and the Built Environment. London: Routledge. 
Skogan, W., Van Craen, M., \& Hennessy, C. (2015). 'Training police for procedural justice.' Journal of Experimental Criminology, 11, 319-334.

Victorian Parliamentary Inquiry Drugs and Crime Prevention Committee. (2013). Inquiry into the Application of Safer Design Principles and Crime Prevention through Environmental Design. Melbourne: Parliament of Victoria.

Weatheritt, M. (1986). Innovations in Policing. London: Croom Helm.

Wootton, A., Armitage, R. \& Monchuk, L., (2007). Greater Manchester Police Architectural Liaison Service Evaluation. Work Package 3 Report - Improvement \& development recommendations. Salford: Design Against Crime Solution Centre, University of Salford. 